\title{
Associations between prevalent multimorbidity combinations and prospective disability and self-rated health among older adults in Europe
}

\author{
Paige E. Sheridan ${ }^{1,2}$, Christine A. Mair ${ }^{4}$ and Ana R. Quiñones ${ }^{3^{*}}$ (1)
}

\begin{abstract}
Background: Multimorbidity is associated with greater likelihood of disability, health-related quality of life, and mortality, greater than the risk attributable to individual diseases. The objective of this study is to examine the association between unique multimorbidity combinations and prospective disability and poor self-rated health (SRH) in older adults in Europe.

Methods: We conducted a prospective analysis using data from the Survey of Health, Ageing and Retirement in Europe in 2013 and 2015. We used hierarchical models to compare respondents with multiple chronic conditions to healthy respondents and respondents reporting only one chronic condition and made within-group comparisons to examine the marginal contribution of specific chronic condition combinations.

Results: Less than $20 \%$ of the study population reported having zero chronic conditions, while $50 \%$ reported having at least two chronic conditions. We identified 380 unique disease combinations among people who reported having at least two chronic conditions. Over 35\% of multimorbidity could be attributed to five specific multimorbidity combinations, and over $50 \%$ to ten specific combinations. Overall, multimorbidity combinations that included high depressive symptoms were associated with increased odds of reporting poor $\mathrm{SRH}$, and increased rates of ADL-IADL disability.

Conclusions: Multimorbidity groups that include high depressive symptoms may be more disabling than combinations that include only somatic conditions. These findings argue for a continued integration of both mental and somatic chronic conditions in the conceptualization of multimorbidity, with important implications for clinical practice and healthcare delivery.
\end{abstract}

Keywords: Multimorbidity, Multiple chronic conditions, Disability, Self-rated health, Depression

\section{Background}

Multimorbidity, most often defined as the presence of two or more co-existing chronic conditions, is highly prevalent among older adults across the world [1-5]. Multimorbidity is associated with greater likelihood of disability [6-10], major depressive disorder [11], lower self-rated health [12], quality of care [13] and increased healthcare utilization and cost $[14,15]$. As the world's

\footnotetext{
* Correspondence: quinones@ohsu.edu

${ }^{3}$ Department of Family Medicine and OHSU-PSU School of Public Health,

Oregon Health \& Science University, Portland, Oregon, USA

Full list of author information is available at the end of the article
}

population ages, there is a growing need for populationbased research in multimorbidity to clarify the complex interactions between health-related quality of life, chronic disease and disability $[16,17]$.

Several seminal works have informed research and clinical practice to shift away from focusing on index, single, and individual chronic diseases and instead consider the full complement of chronic diseases as they cooccur in patients $[1,18,19]$. Yet, there is little consensus on how to measure and operationalize multimorbidity and quantify linkages between important geriatric syndromes and health-related quality of life consequences

(c) The Author(s). 2019 Open Access This article is distributed under the terms of the Creative Commons Attribution 4.0 International License (http://creativecommons.org/licenses/by/4.0/), which permits unrestricted use, distribution, and reproduction in any medium, provided you give appropriate credit to the original author(s) and the source, provide a link to the Creative Commons license, and indicate if changes were made. The Creative Commons Public Domain Dedication waiver (http://creativecommons.org/publicdomain/zero/1.0/) applies to the data made available in this article, unless otherwise stated. 
of multimorbidity among older adult populations. Specifically, gaps in this growing area of research involve increasing the evidence base on the epidemiology of multimorbidity and integrating patient-centered measures to assess the impact of multimorbidity on patients' lives [20, 21].

An increasing number of studies have moved to identify specific multimorbidity patterns among older adults as an advancement over merely counting the total number of chronic conditions. A recent meta-analysis identified three nonrandom patterns of multimorbidity: musculoskeletal, cardiometabolic, and mental health [17]. Specific disease combinations may be more or less disabling than others, therefore it is clinically-relevant to assess outcomes for these combinations [22]. Further, depression is often co-morbid with other chronic conditions, but it is not standard practice to include depression in the operationalization of multimorbidity [23, 24]. While previous studies have examined the prevalence, correlates, and patterns of multimorbidity, and some studies examine the association between multimorbidity and depression [25-27], few have examined the effect of unique multimorbidity profiles, specifically those that incorporate depression into the operationalization of multimorbidity-which may have important and debilitating interactions with co-existing disease-and associations with health-related quality of life outcomes [7, 10, 28].

The purpose of this study is to assess the association between prevalent multimorbidity patterns, including chronic mental and somatic disease that occur in concert, on self-rated health and activities of daily living (ADL) and instrumental activities of daily living (IADL) disability using a cross-national sample of older adults in Europe. We compare respondents with multiple chronic conditions to healthy respondents and respondents reporting only one chronic condition and conduct within-group comparisons to examine the marginal conribution of specific chronic conditions. We discuss implications of unique multimorbidity patterns and examine country-by-country differences within multimorbidity groups. Examining specific multimorbidity patterns will allow for optimization of health care delivery and organization within clinical practice to improve care in these populations.

\section{Methods}

The Survey of Health Ageing and Retirement in Europe (SHARE) is a multidisciplinary and cross-national longitudinal survey of noninstitutionalized Europeans aged 50 and over across 20 European countries and Israel. The target population consists of all persons aged 50 and over at the time of sampling and who have their permanent home in the respective SHARE country. Persons who are hospitalized, out of the country, or unable to speak the country's language at the time of interview were excluded. Computer-assisted personal interviewing (CAPI) was used during face-to-face interviews. Recruitment strategies were country specific. If respondents faced physical or cognitive limitations, it is possible that the respondent is assisted by a proxy respondent. The full description of this survey has been published elsewhere [29].

The most recently available survey data from 2013 and 2015 (Waves 5 and 6) were used in this study. All covariates and exposure were assessed in 2013 and outcomes were assessed in 2015. 47,523 respondents were interviewed in both 2013 and 2015 sample waves, and we excluded 21,352 respondents who were under the age of 65 in 2013, and 862 respondents with one or more missing chronic disease responses. Seventeen respondents had non-positive survey weights and were excluded. Our final study population included 25,239 older adults. Fourteen countries were included in both the 2013 and 2015 SHARE survey: Austria, Germany, Sweden, Spain, Italy, France, Denmark, Switzerland, Belgium, Israel, Czech Republic, Luxembourg, Slovenia and Estonia.

\section{Disability assessment}

SHARE respondents were asked about difficulty performing common everyday tasks to assess physical functioning, six activities of daily living, (ADL; dressing, walking across a room, bathing, eating, transferring from a bed, and toileting) and seven instrumental activities of daily living (IADL; using a map, meal preparation, grocery shopping, using a telephone, taking medication, doing work around the house, and managing money). The primary outcome variable is a combined ADL-IADL index variable assessed in 2015 , created by summing the number of ADL and IADL disability counts for each respondent (range 0-13) [30].

\section{Self-rated health}

Respondents were asked to rate their own health (SRH), on a scale from 0 to 4 (excellent, very good, good, fair, poor) [How would you rate your current health state?]. A higher score indicates poor SRH. The outcome variable is a dichotomous index variable assessed in 2015 for poor SRH (poor, fair) vs. good SRH (good, very good, and excellent).

\section{Chronic diseases}

Respondents were asked about diagnoses of multiple chronic conditions: [Has a doctor ever told you that you had/Do you currently have any of the conditions on this card?]. We used the nine conditions queried in the survey that are associated with disability and poor SRH among older adults for this study: myocardial infarction, high blood pressure, stroke, diabetes, 
cancer, lung disease (excluding asthma), arthritis, Parkinson's and Alzheimer's diagnoses. Persons who indicated "yes" in Wave 5 or any previous wave were recorded as having the chronic condition, unless they disputed having the condition in a later wave. We additionally included a variable for self-reported high depressive symptomatology based on 12 questionnaire items. The instrument used was the EURO-D scale which includes 12 dichotomous indices: depression, pessimism, suicidality, guilt, sleep, interest, irritability, appetite, fatigue, concentration, enjoyment, and tearfulness [31]. Concordant with previous studies, respondents with four or more responses indicating depressive affect on the 12 question Euro-D scale (0-12) were defined as having high depressive symptomatology [31-33].

\section{Covariates}

Sociodemographic covariates were assessed at baseline in 2013 and included age (years), gender ( $1=$ female), education level (pre-primary, primary, lower secondary, upper secondary, post-secondary, 1st tertiary, 2nd tertiary), BMI calculated from interviewer measured height and weight, smoking ( $1=$ current smoking), partnered ( 1 = married or cohabitating) and household net worth quartile in Euros adjusted for inflation.

\section{Statistical analyses}

To assess the relationship between multimorbidity and disability (ADL-IADL index) and poor self-rated health, we examined the prevalence of combinations for participants who reported having at least two chronic conditions. The most prevalent multimorbidity combinations were tabulated and rank-ordered by percent of study participants in each multimorbidity combination. The ten most prevalent groups are examined to ensure sufficient sample size within each multimorbidity combination in regression analyses. Mean ADL-IADL index and mean SRH index were calculated for each multimorbidity group.

We estimated mixed negative binomial and mixed logistic regression models to assess the relationship between multimorbidity group and disability index and dichotomized poor self-rated health, respectively. ADLIADL index and poor SRH reported in 2013 were included in respective models to account for baseline values. The associations in the present study should not be interpreted as causal associations, as we did not assess incident poor SRH and ADL-IADL index. Negative binomial models allow for modeling over-dispersed count data. Country was included as a random effect in all models to account for clustering of study participants by country of residence. We report incidence rate ratios (IRR) and odds ratios (OR) and 95\% confidence intervals. A $p$ value of $<0.01$ was considered significant to account for multiple comparisons. Parameter estimates from negative binomial regression models are interpreted as the log of the ratio of expected counts, or the $\log$ of the rate ratio. These rate ratios can be interpreted as the relative difference in incidence rates between groups.

Across both dependent variables, we evaluated two different comparison groups: 1 ) healthy respondents who reported having no chronic conditions $(n=5,492)$ and 2$)$ respondents who reported having only one chronic condition $(n=8,164)$. We further evaluated these associations among nested groups, or groups that included one additional condition to the existing combination to assess the relative impact of the additional condition between groups. For example: a group that includes both hypertension and arthritis and myocardial infarction would be compared with a group that includes only hypertension and arthritis to assess the relative contribution of myocardial infarction to the combination. An OR or IRR that is different from one in this context indicates that the additional condition contributes to a change in poor SRH or ADL-IADL index, while an OR or IRR that is close to one indicates no additional odds of reporting poor SRH or relative rate of ADL-IADL count associated with the addition of the given condition.

We present both unadjusted and adjusted analyses. Adjusted models include baseline self-rated health or ADL-IADL index, age, gender, education, BMI, current smoking, partnered status, and household net worth. All analyses were weighted using SHARE calibrated longitudinal survey weights to account for sampling. All denominators presented are unweighted and all percentages are weighted using these survey weights. Missing data for income and education was imputed using multiple imputations provided by SHARE [34]. All analyses were conducted using SAS 9.4.

\section{Results}

Our study population consisted of 25,293 respondents across 14 countries and two survey waves in 2013 and 2015. 57\% of participants were female and the mean age was $75.11 \%$ were current smokers and $49 \%$ reported having two or more chronic conditions. The mean number of chronic conditions for the full sample was 1.68 and the mean ADL-IADL index was 0.81 . $19 \%$ of the sample reported having zero chronic conditions, while $50 \%$ reported having at least two chronic conditions. $70 \%$ of the population reported no ADL-IADL limitations and 55\% reported having "good" or better self-rated health. Hypertension was the most prevalent individual chronic condition (49\%) followed by arthritis (34\%) and high depressive symptoms (31\%). Parkinson's and Alzheimer's were the least frequently reported individual chronic conditions. Baseline 
characteristics of the full study sample are summarized in Table 1.

We identified 380 unique disease combinations in people who reported having at least two chronic conditions. Baseline study characteristics among participants with multimorbidity are shown in Additional file 1. Over $35 \%$ of multimorbidity could be attributed to five specific multimorbidity combinations, and over $50 \%$ to ten specific combinations. The top ten multimorbidity categories by prevalence among people who reported having at least two chronic conditions and their respective mean ADL-IADL counts and percent reporting poor $\mathrm{SRH}$ are reported in Table 2. Hypertension was present in eight of the ten groups, while high depressive symptomatology and arthritis were each included in six and five groups, respectively. Among individuals with at least two chronic conditions, 50\% reported high depressive symptomatology.

Figure 1 shows the top ten multimorbidity combinations by country of residence for the sample reporting at least two chronic conditions. Older adults in Italy represented the majority of individuals in five of the ten multimorbidity groups, and older adults in Germany represented the majority if individuals in four of the ten groups. France represented the majority in one multimorbidity group. Overall, Luxembourg, Slovenia, and Estonia had minority representation across all multimorbidity groups.

The results from unadjusted and adjusted negative binomial and logistic models are shown in Table 3. All ten multimorbidity groups were associated with significantly greater rates of ADL-IADL disability compared to healthy respondents with no chronic conditions in unadjusted models. In adjusted models, all groups except for Group 6 were associated with greater rates of ADLIADL disability. When compared with respondents reporting only one condition, Groups $2-5,7,8$ and 9 all had significantly greater ADL-IADL limitations, after adjustment.

All ten multimorbidity groups had increased odds of reporting poor SRH when compared with healthy respondents and respondents with only one chronic condition in unadjusted models. In adjusted models, all groups were associated increased odds of reporting poor $\mathrm{SRH}$ when compared with healthy respondents. All groups were associated with increased odds of reporting poor SRH when compared with respondents with only one chronic condition, except for Group 8.

The head-to-head results from nested group comparisons are shown in Table 4. Unadjusted results are shown in Additional file 2. In nested comparisons, we examine perfect subsets of larger groups to evaluate the relative influence of one additional condition added to a multimorbidity combination. Nested comparisons are
Table 1 Baseline Characteristics of the Study Population, SHARE 2013-2015 $(n=25,293)$

\begin{tabular}{|c|c|}
\hline Characteristic & $N(\%)^{\mathrm{a}} /$ Mean $(\mathrm{SE})$ \\
\hline Female & $14,082(56.82)$ \\
\hline Age, mean & $74.67(0.13)$ \\
\hline Body Mass Index, mean & $26.82(0.16)$ \\
\hline Current Smoking & 2,975 (11.13) \\
\hline Higher Education & $6,349(19.71)$ \\
\hline Partnered & $17,090(59.54)$ \\
\hline \multicolumn{2}{|l|}{ Chronic conditions } \\
\hline Myocardial Infarction & $3,953(15.42)$ \\
\hline Hypertension & $12,296(48.76)$ \\
\hline Stroke & $1,229(4.66)$ \\
\hline Diabetes & $4,025(16.61)$ \\
\hline Cancer & $1,587(7.05)$ \\
\hline Lung Disease & $1,708(7.80)$ \\
\hline High depressive symptoms & $6,883(30.5)$ \\
\hline Parkinson's & $282(1.11)$ \\
\hline Arthritis & $7,365(34.08)$ \\
\hline Alzheimer's & $395(1.61)$ \\
\hline Number of chronic diseases, mean & $1.68(0.04)$ \\
\hline ADL \& IADL index, mean & $0.81(0.06)$ \\
\hline \multicolumn{2}{|l|}{ Self-Rated Health } \\
\hline Excellent & $1,499(4.81)$ \\
\hline Very Good & $3,683(11.31)$ \\
\hline Good & $9,169(38.29)$ \\
\hline Fair & $8,067(33.09)$ \\
\hline Poor & $2,875(12.51)$ \\
\hline Self-Rated Health, mean & $2.37(0.05)$ \\
\hline \multicolumn{2}{|l|}{ Countries } \\
\hline Austria & $1,694(2.34)$ \\
\hline Germany & $1,967(26.89)$ \\
\hline Sweden & $2,258(3.25)$ \\
\hline Spain & 2,863 (14.14) \\
\hline Italy & $2,049(21.65)$ \\
\hline France & $1,726(18.25)$ \\
\hline Denmark & $1,542(1.77)$ \\
\hline Switzerland & $1,419(2.74)$ \\
\hline Belgium & $2,113(3.42)$ \\
\hline Israel & $899(1.20)$ \\
\hline Czech Republic & $2,431(3.18)$ \\
\hline Luxembourg & $465(0.11)$ \\
\hline Slovenia & $1,232(0.64)$ \\
\hline Estonia & $2,635(0.42)$ \\
\hline
\end{tabular}

${ }^{a}$ Values are unweighted counts and weighted percentages $A D L$ Activities of daily living $I A D L$ Instrumental activities of daily living 
Table 2 Mean SRH and ADL-IADL Index and 95\% Confidence Interval of Study Population in 2015 by Multimorbidity Group, SHARE 2013-2015

\begin{tabular}{|c|c|c|c|c|c|}
\hline & & $N^{a}$ & $\%^{b}$ & ADL-IADL (0-13) & Poor SRH \\
\hline & & & & Mean $(95 \% \mathrm{Cl})$ & $\%(\mathrm{SE})$ \\
\hline Group 1 & Hypertension + Arthritis & 1274 & 21.4 & $0.71(0.55,0.87)$ & $50.7(3.0)$ \\
\hline Group 2 & Hypertension + High Depressive Symptoms & 870 & 13.9 & $1.22(0.90,1.53)$ & $54.8(2.3)$ \\
\hline Group 3 & Arthritis + High Depressive Symptoms & 649 & 13.6 & $1.56(1.31,1.80)$ & $65.2(3.1)$ \\
\hline Group 4 & Hypertension + Arthritis + High Depressive Symptoms & 683 & 13.1 & $1.84(1.54,2.14)$ & $72.4(1.8)$ \\
\hline Group 5 & Hypertension + Diabetes Mellitus & 801 & 12.3 & $0.97(0.35,1.58)$ & $50.9(4.1)$ \\
\hline Group 6 & Myocardial Infarction + Hypertension & 572 & 7.3 & $0.81(0.37,1.25)$ & $53.3(3.1)$ \\
\hline Group 7 & Hypertension + Diabetes Mellitus + Arthritis + High Depressive Symptoms & 250 & 5.6 & $2.05(1.55,2.55)$ & $82.2(5.1)$ \\
\hline Group 8 & Hypertension + Diabetes Mellitus + Arthritis & 271 & 5.1 & $0.80(0.63,0.97)$ & $69.8(4.3)$ \\
\hline Group 9 & Hypertension + Diabetes Mellitus + High Depressive Symptoms & 255 & 4.2 & $1.42(0.59,2.26)$ & $72.2(7.0)$ \\
\hline Group 10 & Myocardial Infarction + Hypertension + High Depressive Symptoms & 250 & 3.4 & $1.45(0.89,2.01)$ & $72.6(4.2)$ \\
\hline
\end{tabular}

aalues are unweighted counts

bValues are weighted percentages

$A D L$ Activities of daily living

$I A D L$ Instrumental activities of daily living

SRH Self rated health

grouped by the condition that is added, assessing the marginal impact of the added condition. Groups 4, 7, 9 and 10 included high depressive symptoms added to the combinations represented in groups $1,8,5$ and 6, respectively. After adjustment, all four of these groups had significantly greater ADL-IADL limitations compared with their relative comparison group that did not include high depressive symptoms. Groups 4, 7 and 9 had increased odds of reporting poor SRH when compared with their reference group that did not include high depressive symptoms. The addition of high depressive symptoms to hypertension and myocardial infarction (Group 10 compared to Group 6) did not result in significantly different odds of reporting poor SRH.

All other nested comparisons included the addition of a somatic condition in their comparison group. None of these groups had significantly different odds of reporting poor SRH. All but one of the groups had no change in rates of ADL-IADL disability. The addition of diabetes mellitus to hypertension and high depressive symptoms (Group 9 compared to Group 2)

\begin{tabular}{|l|c|c|c|c|c|c|c|c|c|c|}
\hline & Group 1 & Group 2 & Group 3 & Group 4 & Group 5 & Group 6 & Group 7 & Group 8 & Group 9 & Group 10 \\
\hline Austria & 1.4 & 2.2 & 0.9 & 0.9 & 3.1 & 4.3 & 0.3 & 0.6 & 1.7 & 2.2 \\
\hline Germany & 26.1 & 22.2 & 14.6 & 15.2 & 32.9 & 34.2 & 26.8 & 38.1 & 15.6 & 25.2 \\
\hline Sweden & 3.1 & 2.2 & 1.5 & 1.5 & 2.9 & 2.8 & 0.4 & 1.7 & 1.6 & 2.4 \\
\hline Spain & 15.6 & 16.5 & 15.3 & 17.1 & 15.0 & 17.9 & 21.6 & 19.4 & 26.9 & 12.8 \\
\hline Italy & 17.9 & 29.7 & 23.9 & 37.7 & 20.7 & 16.4 & 29.5 & 13.9 & 28.0 & 29.1 \\
\hline France & 22.0 & 16.0 & 34.5 & 17.8 & 10.2 & 9.8 & 14.5 & 13.0 & 16.6 & 15.9 \\
\hline Denmark & 2.3 & 0.8 & 0.8 & 0.8 & 1.6 & 1.8 & 0.4 & 1.8 & 0.2 & 1.3 \\
\hline Switzerland & 2.8 & 1.5 & 2.1 & 2.3 & 1.4 & 2.6 & 1.2 & 1.4 & 0.6 & 1.5 \\
\hline Belgium & 3.5 & 3.1 & 3.3 & 2.9 & 2.3 & 2.8 & 1.8 & 1.9 & 1.4 & 2.8 \\
\hline Israel & 0.3 & 1.3 & 0.1 & 0.2 & 2.5 & 1.7 & 1.0 & 0.8 & 1.4 & 1.6 \\
\hline Czech & 4.3 & 2.5 & 2.3 & 2.7 & 6.1 & 3.3 & 1.9 & 6.8 & 3.8 & 2.6 \\
\hline Luxembourg & 0.2 & 0.1 & 0.1 & 0.1 & 0.0 & 0.0 & 0.1 & 0.1 & 0.0 & 0.0 \\
\hline Slovenia & 0.2 & 1.1 & 0.4 & 0.3 & 1.0 & 1.3 & 0.2 & 0.1 & 1.5 & 1.2 \\
\hline Estonia & 0.3 & 0.8 & 0.2 & 0.5 & 0.3 & 0.9 & 0.4 & 0.3 & 0.7 & 1.4 \\
\hline
\end{tabular}

Fig. 1 Multimorbidity Group Composition by Country, SHARE 2013-2015 $(n=11,644)$, Reported as Weighted Percentages 


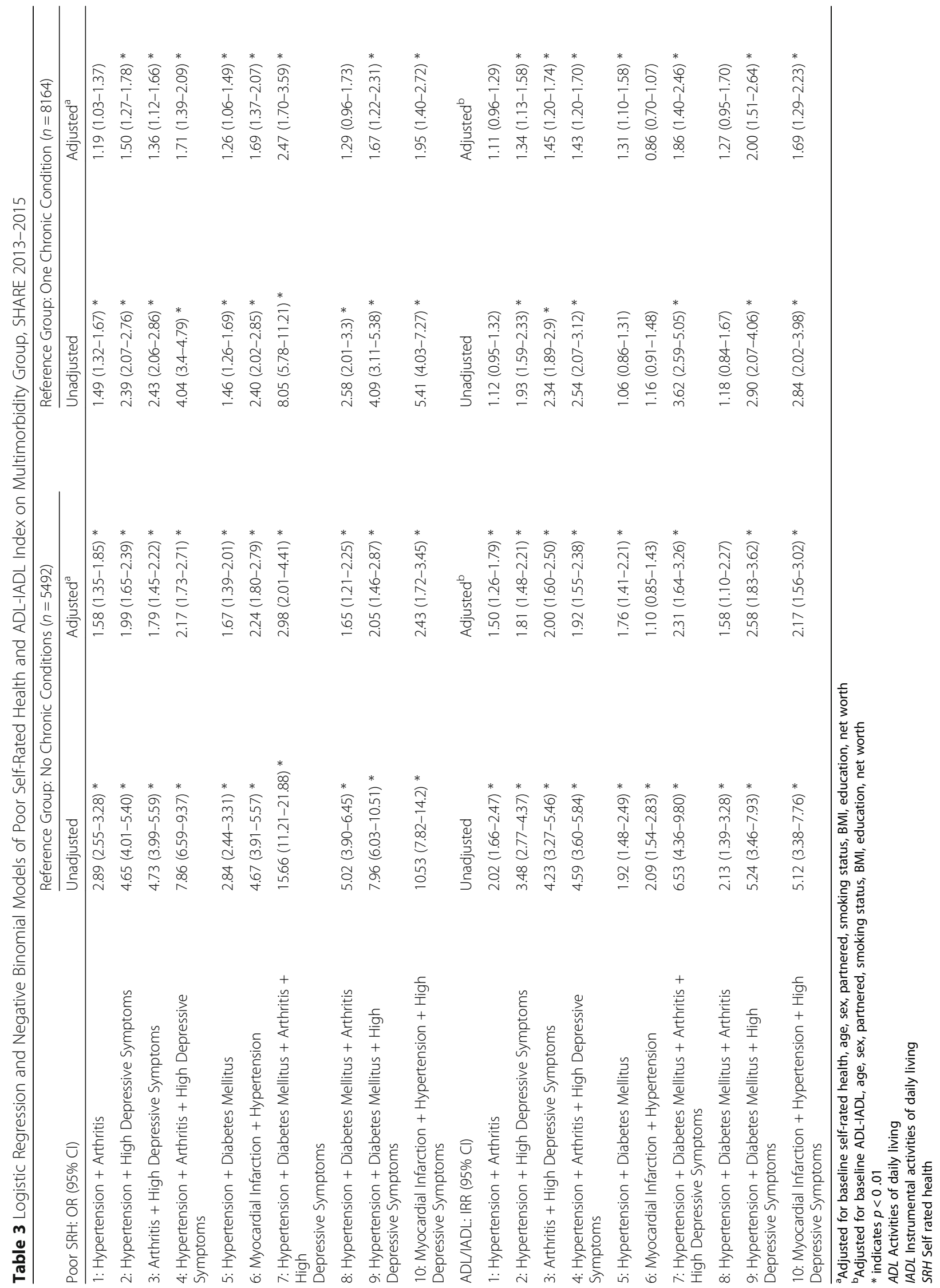


Table 4 Nested Comparisons: Adjusted Logistic Regression and Negative Binomial models of Poor Self-Rated Health and ADL-IADL Index on Multimorbidity Group, SHARE 2013-2015

\begin{tabular}{|c|c|c|c|}
\hline Comparison Group & Reference Group & $\begin{array}{l}\text { Poor SRH: } \\
\text { OR }(95 \% \mathrm{Cl})^{\mathrm{a}}\end{array}$ & $\begin{array}{l}\text { ADL-IADL Index: } \\
\text { IRR }(95 \% \mathrm{Cl})^{\mathrm{b}}\end{array}$ \\
\hline \multicolumn{4}{|l|}{$\begin{array}{l}\text { Addition of High Depressive Symptoms } \\
\text { to Combination }\end{array}$} \\
\hline $\begin{array}{l}\text { 4: Hypertension + Arthritis + High } \\
\text { Depressive Symptoms }\end{array}$ & 1: Hypertension + Arthritis & $1.44(1.14-1.83) *$ & $1.33(1.12-1.59) *$ \\
\hline $\begin{array}{l}\text { 9: Hypertension + Diabetes Mellitus + } \\
\text { High Depressive Symptoms }\end{array}$ & $\begin{array}{l}\text { 5: Hypertension + Diabetes } \\
\text { Mellitus }\end{array}$ & $1.58(1.11-2.24) *$ & $1.74(1.28-2.36) *$ \\
\hline $\begin{array}{l}\text { 10: Myocardial Infarction + Hypertension + } \\
\text { High Depressive Symptoms }\end{array}$ & $\begin{array}{l}\text { 6: Myocardial Infarction + } \\
\text { Hypertension }\end{array}$ & $1.24(0.84-1.84)$ & $1.90(1.46-2.46) *$ \\
\hline $\begin{array}{l}\text { 7: Hypertension + Diabetes Mellitus + Arthritis + } \\
\text { High Depressive Symptoms }\end{array}$ & $\begin{array}{l}\text { 8: Hypertension + Diabetes } \\
\text { Mellitus + Arthritis }\end{array}$ & $2.15(1.33-3.48) *$ & $1.76(1.31-2.38) *$ \\
\hline \multicolumn{4}{|l|}{ Addition of Diabetes Mellitus to Combination } \\
\hline 8: Hypertension + Diabetes Mellitus + Arthritis & 1: Hypertension + Arthritis & $1.12(0.82-1.54)$ & $1.09(0.83-1.44)$ \\
\hline $\begin{array}{l}\text { 9: Hypertension + Diabetes Mellitus + High } \\
\text { Depressive Symptoms }\end{array}$ & $\begin{array}{l}\text { 2: Hypertension }+ \text { High } \\
\text { Depressive Symptoms }\end{array}$ & $1.13(0.80-1.61)$ & $1.42(1.10-1.83) *$ \\
\hline $\begin{array}{l}\text { 7: Hypertension + Diabetes Mellitus + Arthritis + } \\
\text { High Depressive Symptoms }\end{array}$ & $\begin{array}{l}\text { 4: Hypertension + Arthritis + } \\
\text { High Depressive Symptoms }\end{array}$ & $1.44(0.94-2.20)$ & $1.30(1.05-1.61)$ \\
\hline \multicolumn{4}{|l|}{ Addition of Arthritis to Combination } \\
\hline $\begin{array}{l}\text { 4: Hypertension + Arthritis + High Depressive } \\
\text { Symptoms }\end{array}$ & $\begin{array}{l}\text { 2: Hypertension }+ \text { High } \\
\text { Depressive Symptoms }\end{array}$ & $1.14(0.88-1.46)$ & $1.12(0.93-1.33)$ \\
\hline 8: Hypertension + Diabetes Mellitus + Arthritis & $\begin{array}{l}\text { 5: Hypertension + Diabetes } \\
\text { Mellitus }\end{array}$ & $1.13(0.82-1.56)$ & $0.99(0.71-1.38)$ \\
\hline $\begin{array}{l}\text { 7: Hypertension + Diabetes Mellitus + Arthritis + High } \\
\text { Depressive Symptoms }\end{array}$ & $\begin{array}{l}\text { 9: Hypertension + Diabetes } \\
\text { Mellitus + High Depressive } \\
\text { Symptoms }\end{array}$ & $1.42(0.87-2.32)$ & $1.00(0.77-1.29)$ \\
\hline \multicolumn{4}{|l|}{ Addition of Cardiovascular Conditions to Combination } \\
\hline $\begin{array}{l}\text { 10: Myocardial Infarction + Hypertension + } \\
\text { High Depressive Symptoms }\end{array}$ & $\begin{array}{l}\text { 2: Hypertension }+ \text { High } \\
\text { Depressive Symptoms }\end{array}$ & $1.39(0.96-2.01)$ & $1.35(1.06-1.72)$ \\
\hline $\begin{array}{l}\text { 4: Hypertension + Arthritis + High Depressive } \\
\text { Symptoms }\end{array}$ & $\begin{array}{l}\text { 3: Arthritis + High } \\
\text { Depressive Symptoms }\end{array}$ & $1.28(0.98-1.68)$ & $1.00(0.84-1.20)$ \\
\hline
\end{tabular}

${ }^{a}$ Adjusted for baseline self-rated health, age, sex, partnered, smoking status, BMI, education, net worth

${ }^{b}$ Adjusted for baseline ADL-IADL, age, sex, partnered, smoking status, BMI, education, net worth

* indicates $p<0.01$

$A D L$ Activities of daily living

$I A D L$ Instrumental activities of daily living

$S R H$ Self rated health

The bold term is the condition that is added to the combination relative to the reference group

was associated with significantly greater ADL-IADL disability.

\section{Discussion}

This study examined associations between the ten most prevalent multimorbidity groups with disability and poor self-rated health. Multimorbidity was highly prevalent in this sample of older Europeans, with $50 \%$ of the sample reporting at least two chronic conditions. About $48 \%$ of the sample reported poor or fair SRH, and 30\% reported at least one ADL/IADL limitation. Overall, high depressive symptomatology was identified in $50 \%$ of older adults with multimorbidity. Relative to older adults in Europe with one or no chronic conditions, older adults in all multimorbidity groups reported increased disability burden and increased odds of poor self-rated health.
Hypertension was present in nearly all of the most prevalent combinations, and high depressive symptomatology and arthritis were present in a majority of the most prevalent combinations. This population had similar rates of multimorbidity when compared with studies involving US and Australian older adults [6,35], and in other studies of older European adults [15].

We find that multimorbidity group combinations are not distributed evenly across nations, likely reflecting differences in both the demographic composition and multimorbidity burdens across the included European countries. The clustering of multimorbidity categories in certain counties, such as Italy and Germany, is indicative of underlying population and demographic compositional characteristics, as well as the differential distribution of risk factors and chronic disease etiology among 
European countries and region-specific differences in ascertainment and diagnoses of chronic conditions. Further exploration of specific multimorbidity patterns within European countries is warranted.

Multimorbidity combinations that include high depressive symptoms are associated with high rates of prospective ADL-IADL disability, and increased odds of reporting poor SRH in this study. It is plausible that, on average, the addition of high depressive symptoms to any chronic condition or combination of chronic conditions may be more disabling or associated with worse SRH than the addition of an individual somatic condition. When we examine nested multimorbidity groups, we find that all four groups that include high depressive symptoms have higher ADL-IADL burden, and three of the four groups have increased odds of reporting poor SRH. Concurrently, when we examine nested groups that only include the addition of a somatic condition, we found no differences in odds of reporting poor SRH. The ORs in these comparisons are close to one, possibly indicating that the addition of a somatic condition alone to an individual with high depressive symptoms has a relatively small effect on SRH. We see a similar pattern when looking at ADL-IADL index, where almost all groups that include the addition of a somatic condition do not have significantly different rates of ADL-IADL disability, with IRR close to one. However, we do find increased rates of ADL-IADL disability in one somatic condition group, the comparison of Group 9 with Group 2, where diabetes mellitus is added to high depressive symptoms and hypertension.

Taken together, these results suggest that the addition of high depressive symptomatology alone may be considerably more disabling than the addition of another somatic condition. These findings are consistent with previous studies in the US that conceptualized multimorbidity combining somatic and mental conditions $[7,22]$. The present study provides potential evidence that this association extends cross-nationally. To our knowledge this is one of the first studies to examine associations between unique multimorbidity combinations and associations with prospective self-rated health and ADL-IADL disability in Europe. Our analysis of a large, cross-nationally representative, longitudinal dataset allows us to assess associations while accounting for prior SRH and ADL-IADL disability to account for temporal sequence. Most importantly, these findings underscore the potential multiplicative effect chronic conditions may have on SRH and disability and highlight the potential role of high depressive symptomatology as a key co-morbid condition in the operationalization of multimorbidity.
This study has several noteworthy limitations. First, the use of self-reported measures of chronic health conditions and health states may under or over-estimate the true prevalence of these conditions in this older population, particularly among lower socioeconomic and lower education groups [36]. However, several studies have shown reasonable concordance between participant reports of physician-diagnosed conditions and administrative and medical record data sources [37, 38]. Second, condition severity could not be assessed and may be an important consideration in comparing multimorbidity combinations and associations with the outcomes of interest. However, chronic disease severity is notoriously difficult to capture with high reliability in populationbased data sources [39]. In sensitivity analyses, we observed that less than $1 \%$ of participants who reported having a chronic condition in wave 5 reported no longer having that condition in wave 6 , which would indicate a possible misunderstanding about the presence or absence of the condition. Still, it is important to assess self-report of chronic conditions, because they represent individuals' beliefs about the chronic diseases they have and dictate self-management behaviors. Future research should further clarify chronic disease status and ascertainment in longitudinal studies-possibly with the inclusion of information treatments and medication use to confirm diagnoses present-to better assess the development and progression of multimorbidity over time [40]. In addition, better specifying the psychosocial risk factors (and protective, buffering factors) associated with multimorbidity is an important area of research that should be prioritized in future studies.

\section{Conclusions}

This is the first cross-national study to examine the association between unique multimorbidity combinations and ADL-IADL disability and self-rated health. We find that multimorbidity is highly prevalent among European older adults and is associated with higher rates of disability and increased odds of poor self-rated health. Finally, multimorbidity combinations that include high depressive symptoms may be more disabling than combinations that include only somatic conditions. These findings argue for a continued integration of both mental as well as somatic chronic conditions in the conceptualization of multimorbidity, with important implications for clinical practice and healthcare delivery. Organizing health care delivery to better address the multiplicative effect of the presence of multiple chronic conditions, particularly depression, should be prioritized. European health systems may want to emphasize management of chronic mental health conditions for patients with multiple chronic conditions to improve health outcomes associated with aging. 


\section{Additional files}

Additional file 1: Baseline Characteristics of the Study Population with Two or More Chronic Conditions, SHARE 2013-2015 $(n=11,644)$. (DOCX $17 \mathrm{~kb}$ )

Additional file 2: Table S4. Nested Comparisons: Unadjusted Logistic Regression and Negative Binomial models of Poor Self-Rated Health and ADL-IADL Index on Multimorbidity Group, SHARE 2013-2015. (DOCX $17 \mathrm{~kb})$

\section{Abbreviations}

ADL: Activities of daily living; CAPI: Computer-assisted personal interviewing; IADL: Instrumental activities of daily living; $\mathrm{SRH}$ : Self rated health

\section{Authors' contributions}

PS helped plan the study, performed the statistical analyses and was a major contributor in writing the manuscript. CM helped plan the study and was a major contributor in writing the manuscript. AQ helped plan the study, assisted with data analyses and was a major contributor in writing the manuscript. All authors read and approved the final manuscript.

\section{Funding}

This study was supported by the American Diabetes Association career development award (ADA 7-13-CD-08) and the National Institutes of Health National Institute on Aging (R01AG055681) to Dr. Quiñones. The funding body was not involved in the design of the study; collection, analysis, interpretation of data; or in writing of the manuscript.

The SHARE data collection has been primarily funded by the European Commission through FP5 (QLK6-CT-2001-00360), FP6 (SHARE-I3: RII-CT-2006062193, COMPARE: CIT5-CT-2005-028857, SHARELIFE: CIT4-CT-2006-028812) and FP7 (SHARE-PREP: №211909, SHARE-LEAP: N²27822, SHARE M4: $N^{\circ}$ 261982). Additional funding from the German Ministry of Education and Research, the Max Planck Society for the Advancement of Science, the U.S. National Institute on Aging (U01_AG09740-13S2, P01_AG005842, P01_AG08291, P30_AG12815, R21_AG025169, Y1-AG-4553-01, IAG_BSR06-11, OGHA_04-064, HHSN271201300071C) and from various national funding sources is gratefully acknowledged (see www.share-project.org).

\section{Availability of data and materials}

The datasets generated and/or analyzed during the current study are available in the Survey of Health Ageing and Retirement repository, http:// www.share-project.org, [Börsch-Supan, A. (2018). Survey of Health, Ageing and Retirement in Europe (SHARE) Wave 5. Release version: 6.1.0. SHARE-ERIC. Data set. DOI: https://doi.org/10.6103/SHARE.w5.611; Börsch-Supan, A. (2018). Survey of Health, Ageing and Retirement in Europe (SHARE) Wave 6. Release version: 6.1.0. SHARE-ERIC. Data set. DOl: https://doi.org/10.6103/SHARE. w6.611].

\section{Ethics approval and consent to participate}

The Institutional Review Board of Johns Hopkins University approved the National Health and Aging Trends Study (NHATS). The current study involved secondary data analysis of NHATS data and was approved by the Institutional Review Board of Oregon Health \& Science University.

\section{Consent for publication}

Not applicable

\section{Competing interests}

The authors declare that they have no competing interests.

\section{Author details}

'Department of Family Medicine and Public Health, University of California, San Diego School of Medicine, San Diego, California, USA. ${ }^{2}$ Department of Public Health, San Diego State University School of Public Health, San Diego, California, USA. ${ }^{3}$ Department of Family Medicine and OHSU-PSU School of Public Health, Oregon Health \& Science University, Portland, Oregon, USA. ${ }^{4}$ Department of Sociology \& Anthropology, University of Maryland, Baltimore County, Baltimore, MD, USA.
Received: 13 August 2018 Accepted: 15 July 2019

Published online: 27 July 2019

\section{References}

1. Tinetti ME, Fried TR, Boyd CM. Designing health care for the most common chronic condition-multimorbidity. JAMA. 2012;307(23):2493-4.

2. Afshar S, Roderick PJ, Kowal P, Dimitrov BD, Hill AG. Multimorbidity and the inequalities of global ageing: a cross-sectional study of 28 countries using the world health surveys. BMC Public Health. 2015;15:776.

3. Salive ME. Multimorbidity in Older Adults. Epidemiol Rev. 2013;35(1):75-83.

4. Marengoni A, Angleman S, Melis R, Mangialasche F, Karp A, Garmen A, et al. Aging with multimorbidity: a systematic review of the literature. Ageing Res Rev. 2011;10(4):430-9.

5. Nielsen CR, Halling A, Andersen-Ranberg K. Disparities in multimorbidity across Europe: findings from the SHARE survey. Eur Geriatr Med. 8(1):16-21.

6. Jindai K, Nielson CM, Vorderstrasse BA, Multimorbidity QAR, Functional Limitations Among Adults 65 or Older. NHANES 2005-2012. Prev Chronic Dis. 2016;13:E151.

7. Quiñones AR, Markwardt S, Botoseneanu A. Multimorbidity combinations and disability in Older adults. J Gerontol Ser A Biol Med Sci. 2016;71(6):823-30.

8. Bleijenberg N, Zuithoff NPA, Smith AK, de Wit NJ, Schuurmans MJ. Disability in the individual $A D L, I A D L$, and mobility among Older adults: a prospective cohort study. J Nutr Health Aging. 2017;21(8):897-903.

9. Hajek A, König H-H. Longitudinal predictors of functional impairment in Older adults in Europe - evidence from the survey of health, ageing and retirement in Europe. PLoS One. 2016;11(1):e0146967.

10. Rivera-Almaraz A, Manrique-Espinoza B, Avila-Funes JA, Chatterji S, Naidoo $N$, Kowal P, et al. Disability, quality of life and all-cause mortality in older Mexican adults: association with multimorbidity and frailty. BMC Geriatr. 2018;18(1):236.

11. Ryu E, Chamberlain AM, Pendegraft RS, Petterson TM, Bobo WV, Pathak J. Quantifying the impact of chronic conditions on a diagnosis of major depressive disorder in adults: a cohort study using linked electronic medical records. BMC Psychiatry. 2016;16:114.

12. Mavaddat N, Valderas JM, van der Linde R, Khaw KT, Kinmonth AL. Association of self-rated health with multimorbidity, chronic disease and psychosocial factors in a large middle-aged and older cohort from general practice: a cross-sectional study. BMC Fam Pract. 2014;15:185.

13. Zulman DM, Asch SM, Martins SB, Kerr EA, Hoffman BB, Goldstein MK. Quality of Care for Patients with multiple chronic conditions: the role of comorbidity interrelatedness. J Gen Intern Med. 2014;29(3):529-37.

14. Lehnert T, Heider D, Leicht H, Heinrich S, Corrieri S, Luppa M, et al. Review: health care utilization and costs of elderly persons with multiple chronic conditions. Med Care Res Rev. 2011:68(4):387-420.

15. Palladino R, Tayu Lee J, Ashworth M, Triassi M, Millett C. Associations between multimorbidity, healthcare utilisation and health status: evidence from 16 European countries. Age Ageing. 2016;45(3):431-5.

16. Tisminetzky M, Bayliss EA, Magaziner JS, Allore HG, Anzuoni K, Boyd CM, et al Research priorities to advance the health and health Care of Older Adults with multiple chronic conditions. J Am Geriatr Soc. 2017;65(7):1549-53.

17. Prados-Torres A, Calderón-Larrañaga A, Hancco-Saavedra J, Poblador-Plou B, van den Akker M. Multimorbidity patterns: a systematic review. J Clin Epidemiol. 2014;67(3):254-66.

18. Boyd CM, Ritchie CS, Tipton EF, Studenski SA, Wieland D. From bedside to bench: summary from the American Geriatrics Society/National Institute on Aging research conference on comorbidity and multiple morbidity in Older adults. Aging Clin Exp Res. 2008;20(3):181-8.

19. Tinetti ME, Fried T. The end of the disease era. Am J Med. 2004;116(3):179-85.

20. Parekh AK, Goodman RA, Gordon C, Koh HK. Managing multiple chronic conditions: a strategic framework for improving health outcomes and quality of life. Public health reports (Washington, DC : 1974). 2011;126(4):460-71.

21. Satariano WA, Boyd CM. Improving the evidence base on multimorbidities through better research: a commentary on the U.S. HHS initiative, multiple chronic conditions: a strategic framework. J Comorbidity. 2013;3(2):18-21.

22. Quinones AR, Markwardt S, Thielke S, Rostant O, Vasquez E, Botoseneanu A. Prospective disability in different combinations of somatic and mental Multimorbidity. J Gerontol A Biol Sci Med Sci. 2018;73(2):204-10.

23. Moussavi S, Chatterji S, Verdes E, Tandon A, Patel V, Ustun B. Depression, chronic diseases, and decrements in health: results from the world health surveys. Lancet. 2007;370(9590):851-8. 
24. Ford ES, Croft JB, Posner SF, Goodman RA, Giles WH. Co-occurrence of leading lifestyle-related chronic conditions among adults in the United States, 2002-2009. Prev Chronic Dis. 2013;10:E60.

25. Chima CC, Salemi JL, Wang M, Mejia de Grubb MC, Gonzalez SJ, Zoorob RJ. Multimorbidity is associated with increased rates of depression in patients hospitalized with diabetes mellitus in the United States. J Diabetes Complicat. 2017;31(11):1571-9.

26. Camargo-Casas S, Suarez-Monsalve S, Zepeda MUP, Garcia-Pena C, CanoGutierrez CA. Multimorbidity, depressive symptoms, and self-reported health in Older adults: a secondary analysis of the Sabe Bogota study. Rev Invest Clin. 2018;70(4):192-7.

27. Rast $\mathrm{P}$, Rush J, Piccinin A, Hofer SM. The identification of regions of significance in the effect of multimorbidity on depressive symptoms using longitudinal data: an application of the Johnson-Neyman technique. Gerontology. 2014;60(3):274-81.

28. Schafer I, von Leitner EC, Schon G, Koller D, Hansen H, Kolonko T, et al. Multimorbidity patterns in the elderly: a new approach of disease clustering identifies complex interrelations between chronic conditions. PLoS One. 2010;5(12):e15941.

29. Borsch-Supan A, Brandt M, Hunkler C, Kneip T, Korbmacher J, Malter F, et al. Data resource profile: the survey of health, ageing and retirement in Europe (SHARE). Int J Epidemiol. 2013:42(4):992-1001.

30. Ng X, Quinn CC, Burcu M, Harrington D. Assessment of an expanded functional disability scale for Older adults with diabetes. J Appl Gerontol. 2014;35(5):529-48.

31. Prince MJ, Reischies F, Beekman AT, Fuhrer R, Jonker C, Kivela SL, et al, Development of the EURO-D scale--a European, union initiative to compare symptoms of depression in 14 European centres. $\mathrm{Br} \mathrm{J}$ Psychiatry. 1999;174:330-8

32. Castro-Costa E, Dewey M, Stewart R, Banerjee S, Huppert F, Mendonca-Lima C, et al. Ascertaining late-life depressive symptoms in Europe: an evaluation of the survey version of the EURO-D scale in 10 nations. The SHARE project. Int J Methods Psychiatr Res. 2008;17(1):12-29.

33. Castro-Costa E, Dewey M, Stewart R, Banerjee S, Huppert F, Mendonca-Lima C, et al. Prevalence of depressive symptoms and syndromes in later life in ten European countries. Br J Psychiatry. 2007;191(5):393.

34. In: Börsch-Supan AAJ, H., editor. The Survey of Health, Aging, and Retirement in Europe - Methodology Mannheim: Mannheim Research Institute for the Economics of Aging (MEA) 2005.

35. Islam MM, Valderas JM, Yen L, Dawda P, Jowsey T, McRae IS. Multimorbidity and comorbidity of chronic diseases among the senior Australians: prevalence and patterns. PLoS One. 2014;9(1):e83783.

36. Fortin M, Stewart M, Poitras M-E, Almirall J, Maddocks H. A systematic review of prevalence studies on Multimorbidity: toward a more uniform methodology. Ann Fam Med. 2012;10(2):142-51.

37. Day HR, Parker J, National Center for Health Statistics (U.S.). Self-report of diabetes and claims-based identification of diabetes among Medicare beneficiaries. Available from: http://purl.fdlp.gov/GPO/gpo47141.

38. Okura Y, Urban LH, Mahoney DW, Jacobsen SJ, Rodeheffer RJ. Agreement between self-report questionnaires and medical record data was substantial for diabetes, hypertension, myocardial infarction and stroke but not for heart failure. J Clin Epidemiol. 2004;57(10):1096-103.

39. Boyd CM, Weiss CO, Halter J, Han KC, Ershler WB, Fried LP. Framework for evaluating disease severity measures in older adults with comorbidity. J Gerontol A Biol Sci Med Sci. 2007;62(3):286-95.

40. Cigolle CT, Nagel CL, Blaum CS, Liang J, Quinones AR. Inconsistency in the self-report of chronic diseases in panel surveys: developing an adjudication method for the health and retirement study. J Gerontol Ser B Psychol Sci Soc Sci. 2016.

\section{Publisher's Note}

Springer Nature remains neutral with regard to jurisdictional claims in published maps and institutional affiliations.

Ready to submit your research? Choose BMC and benefit from:

- fast, convenient online submission

- thorough peer review by experienced researchers in your field

- rapid publication on acceptance

- support for research data, including large and complex data types

- gold Open Access which fosters wider collaboration and increased citations

- maximum visibility for your research: over $100 \mathrm{M}$ website views per year

At $\mathrm{BMC}$, research is always in progress.

Learn more biomedcentral.com/submissions 